ARTICLE

Received 9 Jul 2012 | Accepted 14 Jan 2013 | Published 26 Feb 2013

DOl: $10.1038 /$ ncomms2496

\title{
Enhanced dihydropyridine receptor calcium channel activity restores muscle strength in JP45/CASQ1 double knockout mice
}

Barbara Mosca', Osvaldo Delbono², Maria Laura Messi ${ }^{2}$, Leda Bergamelli', Zhong-Min Wang², Mirko Vukcevic ${ }^{3}$, Ruben Lopez ${ }^{3}$, Susan Treves ${ }^{1,3}$, Miyuki Nishi ${ }^{4}$, Hiroshi Takeshima4 ${ }^{4}$ Cecilia Paolini $^{5}$, Marta Martini ${ }^{6}$, Giorgio Rispoli ${ }^{6}$, Feliciano Protasi ${ }^{5}$ \& Francesco Zorzato ${ }^{1,3}$

Muscle strength declines with age in part due to a decline of $\mathrm{Ca}^{2}+$ release from sarcoplasmic reticulum calcium stores. Skeletal muscle dihydropyridine receptors $\left(\mathrm{Ca}_{v} 1.1\right)$ initiate muscle contraction by activating ryanodine receptors in the sarcoplasmic reticulum. $\mathrm{Ca}_{\mathrm{v}} \mathrm{1} 1 \mathrm{1}$ channel activity is enhanced by a retrograde stimulatory signal delivered by the ryanodine receptor. JP45 is a membrane protein interacting with $\mathrm{Ca}_{\mathrm{v}} 1.1$ and the sarcoplasmic reticulum $\mathrm{Ca}^{2}+$ storage protein calsequestrin (CASQ1). Here we show that JP45 and CASQ1 strengthen skeletal muscle contraction by modulating $\mathrm{Ca}_{\mathrm{v}} 1.1$ channel activity. Using muscle fibres from JP45 and CASQ1 double knockout mice, we demonstrate that $\mathrm{Ca}^{2+}$ transients evoked by tetanic stimulation are the result of massive $\mathrm{Ca}^{2}{ }^{2}$ influx due to enhanced $\mathrm{Ca}_{v} 1.1$ channel activity, which restores muscle strength in JP45/CASQ1 double knockout mice. We envision that JP45 and CASQ1 may be candidate targets for the development of new therapeutic strategies against decay of skeletal muscle strength caused by a decrease in sarcoplasmic reticulum $\mathrm{Ca}^{2+}$ content.

\footnotetext{
${ }^{1}$ Department of Experimental and Diagnostic Medicine, General Pathology section, University of Ferrara, Via Borsari 46, Ferrara 44121, Italy. ${ }^{2}$ Department of Physiology and Pharmacology, Wake Forest University School of Medicine, Winston-Salem, North Carolina 27157, USA. ${ }^{3}$ Department of Biomedicine and Anesthesiology, Basel University Hospital, Hebelstrasse 20, Basel 4031, Switzerland. ${ }^{4}$ Department of Biological Chemistry, Graduate School of Pharmacological Sciences, Kyoto University, Kyoto 606-8501, Japan. ${ }^{5}$ CeSI-Center for Research on Ageing \& DNI-Department of Neuroscience and Imaging, University Gabriele d Annunzioof Chieti, Via Colle dell'Ara, 66100 Chieti, Italy. ${ }^{6}$ Department of Biology and Evolution, Physiology and Biophysics University of Ferrara, Via Borsari 46, Ferrara 44121, Italy. Correspondence and requests for materials should be addressed to F.Z. (email: fzorzato@uhbs.ch).
} 
A ctivation of skeletal muscle contraction is initiated by the propagation of the action potential deep into the muscle fibre by means of the transverse tubular system ( $T$ system $)^{1-3}$. T-tubule depolarization causes massive release of $\mathrm{Ca}^{2+}$ from the sarcoplasmic reticulum (SR) throughout the entire length of the muscle fibre by a process called excitationcontraction coupling 1,2 . Loss of muscle function has been recognized as a debilitating and life-threatening condition not only in the elderly, but also in cachexia in cancer patients and in all those clinical conditions associated with prolonged bed rest ${ }^{4,5}$. The decay of muscle strength is caused by several factors, including a decrease of releasable calcium from the skeletal muscle SR calcium store ${ }^{6,7}$.

EC coupling is operated by a macromolecular complex comprising the $\alpha_{1}$-subunit of the voltage-dependent L-type $\mathrm{Ca}^{2+}$ channel (dihydropyridine receptor, DHPR, $\mathrm{Ca}_{\mathrm{v}} 1.1$ ), the ryanodine receptor (RyR) and calsequestrin (CASQ1) ${ }^{8}$, in the contact region between the T system and the SR membrane ${ }^{3}$. $\mathrm{Ca}_{\mathrm{v}} 1.1$ acts as a voltage sensor and generates orthograde signals that cause opening of the RyR whereby $\mathrm{Ca}^{2+}$ is released from the SR into the myoplasm, leading to activation of the contractile proteins ${ }^{1}$. Analysis of voltage-dependent calcium currents in RyR1 knockout (KO) muscle cells was fundamental to clarify the signalling mechanisms between the RyR and $\mathrm{Ca}_{\mathrm{v}} 1.1$. It is now accepted that the RyR1 not only receives an orthograde signal from $\mathrm{Ca}_{\mathrm{v}} 1.1$, but also generates a retrograde signal which is important for the activation of $\mathrm{Ca}_{\mathrm{v}} 1.1$ channel activity ${ }^{9,10}$. The mechanism by which the retrograde $\mathrm{Ca}^{2+}$ current enhancement is modulated and its exact physiological role remain elusive.
Although calcium influx across the sarcolemma is thought to be non relevant for muscle contraction ${ }^{11}$, it has been proposed that it may have a role in replenishing the SR during sustained muscle contractions ${ }^{12}$. Two different modes of calcium influx in skeletal muscle have been described: (i) calcium influx via $\mathrm{Ca}_{\mathrm{v}} 1.1$ associated with prolonged membrane depolarization is referred to as excitation-coupled calcium entry $(\mathrm{ECCE})^{10}$, (ii) calcium influx via STIM1 and OraI1 stimulated by internal store depletion is referred to as store-operated calcium entry $(\mathrm{SOCE})^{13-15}$. However, the analysis of macroscopic calcium currents in adult muscle fibres recorded under voltage clamp condition ${ }^{16}$ suggests that both voltage-dependent calcium release and/or SR calcium depletion are not sufficient to activate inward calcium currents and thus challenged the physiological relevance of ECCE and SOCE in adult mammalian fibres. Nevertheless, calcium influx in muscle cells deserves further investigation, because of the potential impact of calcium influx in determining releasable SR calcium content ${ }^{17}$, a crucial factor for proper sustained muscle force development ${ }^{6,7,18}$.

Calcium influx in skeletal muscle is affected by drugs ${ }^{19,20}$ and by accessory proteins such as junctophyllin and mitsugumin-29, two proteins localized in the membrane compartment which form the junction between $T$ tubules and $\mathrm{SR}^{12,21}$. $\mathrm{T}$ tubules-SR junction membranes encompasses also JP45, a developmentally regulated $45-\mathrm{kDa}$ transmembrane protein that interacts via its luminal carboxy-terminal domain with CASQ1, the major calcium storage protein of SR, and with its amino terminal domain with $\mathrm{Ca}_{\mathrm{v}} 1.1^{22}$. Ablation of calsequestrin 1 in skeletal muscle fibres results in a decrease of total calcium
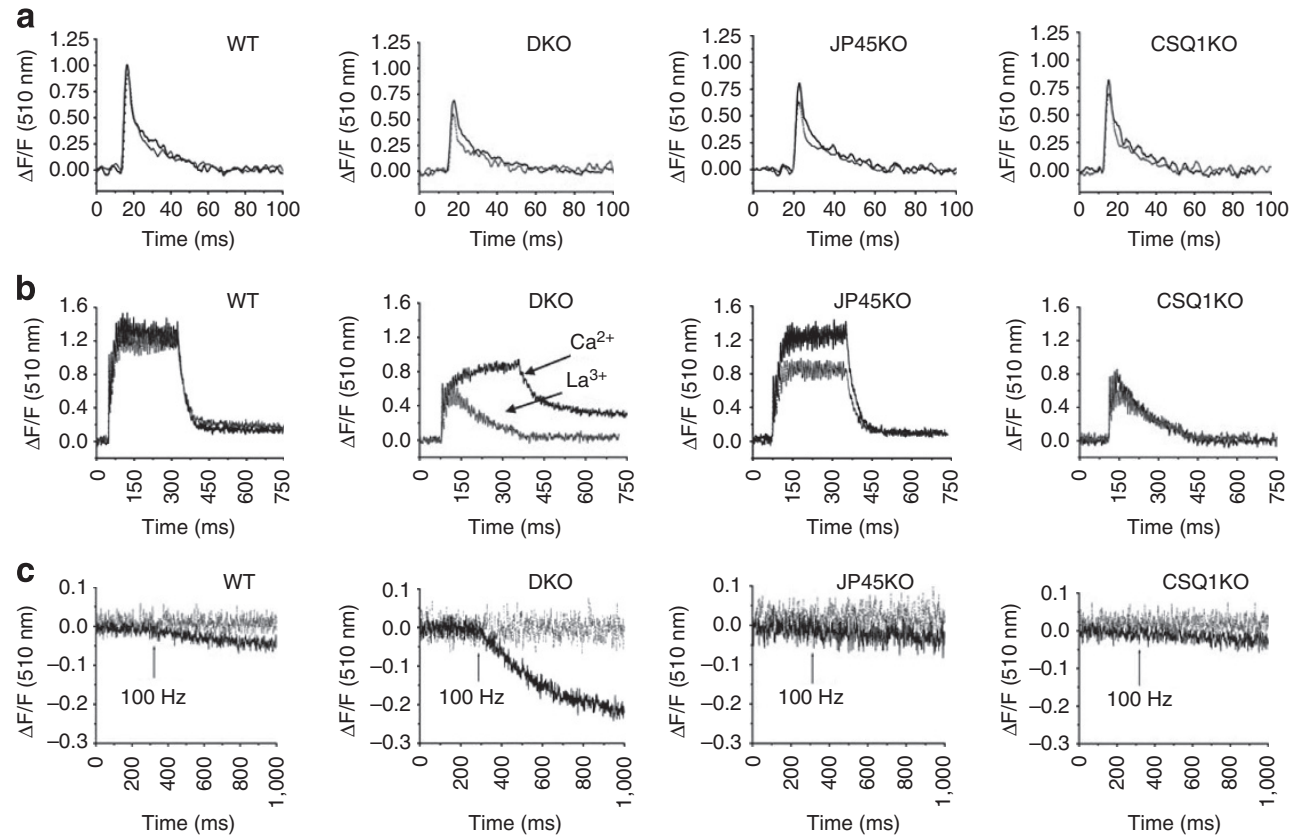

Figure 1 | $\mathbf{C a}^{2}+$ transients and $\mathbf{M n}^{\mathbf{2}+}$ quenching in FDB fibres from single and DKO mice. FDB fibres were loaded with the fast low-affinity $\mathrm{Ca}{ }^{2}+\mathrm{dye}$ Mag-Fluo-4AM ${ }^{21,22}$. (a) $\mathrm{Ca}^{2+}$ transients were triggered by supramaximal field stimulation with single pulses of 0.5 ms duration. Continuous lines: $\mathrm{Ca}^{2+}$ transients recordings in an external solution containing $1.8 \mathrm{mM} \mathrm{CaCl}_{2}$. Overall ANOVA $P$-value $<0.0001$; multicomparison Dunnet's ANOVA post test shows difference between of the peak calcium values: WT versus DKO $P<0.01$, WT versus JP45 KO $P<0.01$; WT versus CASQ1 KO $P<0.01$; dotted grey lines: $\mathrm{Ca}^{2+}$ transients recordings in an external solution containing $100 \mu \mathrm{M} \mathrm{La}{ }^{3+}$. Overall ANOVA $P$-value $<0.0001$; multicomparison Dunnet's ANOVA post test shows difference between of the peak calcium values: WT versus DKO $P<0.01$, WT versus JP45 KO $P<0.01$, WT versus CASQ1 KO $P<0.01$. (b) Recording of $\mathrm{Ca}^{2}+$ transients upon stimulation with repetitive pulses at $100 \mathrm{~Hz}$ for $300 \mathrm{~ms}$ duration. Black and grey lines show recordings in the presence of $1.8 \mathrm{mM} \mathrm{Ca}^{2+}$ and $100 \mu \mathrm{M} \mathrm{La}^{3+}$ in the external solution, respectively. In the presence of $\mathrm{La}^{3+}$, the overall ANOVA $P$-value is $<0.0001$; multicomparison Dunnet's ANOVA post test shows differences: WT versus DKO $P<0.01$, WT versus JP45 KO $P<0.05$, WT versus CASQ1 KO $P<0.01$. (c) $\mathrm{Mn}^{2}+$ quenching of Fura-2 fluorescence. Black lines: $\mathrm{Mn}^{2}+$ influx was triggered by repetitive pulses at $100 \mathrm{~Hz}$ (arrow) for $300 \mathrm{~ms}$ duration. Overall ANOVA $P$-value $<0.0001$; multicomparison Dunnet's ANOVA post test shows differences: WT versus DKO $P<0.01$. Dotted grey lines: Mn ${ }^{2+}$ quenching recordings in the presence of $50 \mu \mathrm{M}$ nifedipine in the external solution. 
a

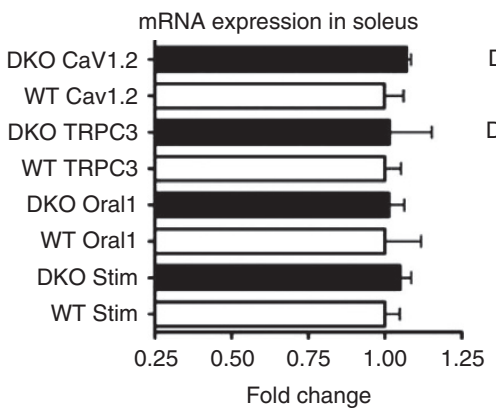

mRNA expression in EDL

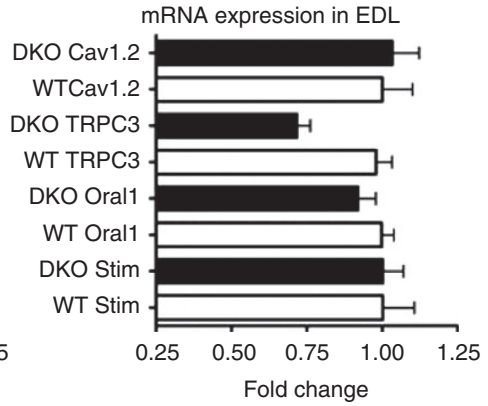

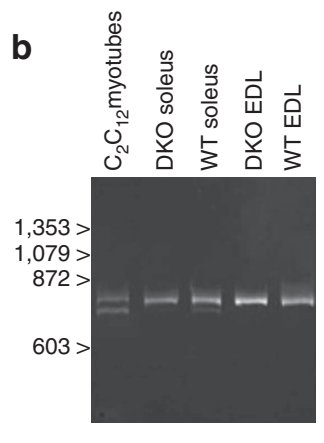

Figure 2 | Expression of calcium entry proteins in fast and slow muscles from DKO mice. (a) Real-time reverse transcription (RT) PCR from soleus and EDL of wild-type and DKO mice. Real-time RT PCR was carried out as previously described ${ }^{41}$. Briefly, total RNA was extracted using TRIzol reagent from Soleus or EDL muscles after frozen tissue homogenization, and Cav1.2, TRPC3, Oral1 and STIM1 gene expression was evaluated by quantitative real-time PCR. Boxes represent the mean ( \pm s.e.m.) fold change compared with values obtained from WT for each gene of interest. Gene expression levels were normalized to the expression of the Tata box-binding protein (TBP) and desmin, whose expression was equal between wild-type and KO animals. Pooled data are results carried out on muscles from 5 to 7 different mice. (b) Expression of $\triangle 29 \mathrm{Ca}_{\mathrm{v}} 1.1$ isoform mRNA in EDL and Soleus from 1-month-old WT and DKO mice. The expression of neonatal $\Delta 29$ Cav1.1 isoforms allele (lower band) is present in mRNA from C2C12 myotubes. The $\Delta 29$ Cav1.1 isoforms could be absent or below the detection limit of PCR in EDL. Soleus displays a faint band corresponding to the $\Delta 29$ exon Ca 1.1 transcript.

release from the SR, which leads to impaired muscle performance and contractile activation ${ }^{23-26}$. Chronic depletion of JP45 induces a decrease of muscle strength in 3-month-old JP45 KO mice ${ }^{27}$. The decay in strength is apparently not linked to atrophy, but to defects in the EC-coupling machinery caused by alteration of the functional expression of DHPR $\mathrm{Ca}_{\mathrm{v}} 1.1$ in the T-tubular network.

In the present study, we tested the hypothesis that the skeletal muscle $\mathrm{Ca}_{\mathrm{v}} 1.1$ channel activity is not only regulated by the RyR, but additionally by the JP45/CASQ1 complex. We generated double JP45 and CASQ1 KO (DKO) and compared their $\mathrm{Ca}_{\mathrm{v}} 1.1$ mediated $\mathrm{Ca}^{2+}$ signals to those observed in WT and each single JP45 and CASQ1 KO mice. Our results show that in DKO mice, tetanic stimulation of skeletal muscle fibres causes massive $\mathrm{Ca}^{2+}$ influx due to enhanced $\mathrm{Ca}_{\mathrm{v}} 1.1$ channel activity and this $\mathrm{Ca}^{2+}$ influx restores muscle strength. By using this animal model, we have unveiled a signalling pathway which may be an important target for drugs against the loss of skeletal muscle strength caused by decrease of the SR calcium content.

\section{Results}

Calcium transient in flexor digitorum brevis fibres. We compared $\mathrm{Ca}^{2+}$ homoeostasis in WT, single JP45 and CSQ1 KO and DKO using the ratiometric $\mathrm{Ca}^{2}+$ indicator Indo- 1 and found that the resting calcium concentration was increased in DKO $1.15 \pm 0.23^{*}(n=48)$ fibres compared with WT $(0.92 \pm 0.10$, $n=40)$, JP45 null $(1.03 \pm 0.18, n=42)$ and CASQ1 null $(0.95 \pm 0.11)$ fibres $\left(F_{405} / F_{480}\right.$ indo- 1 ratio values are mean \pm s.d.; ${ }^{\star}$ WT versus DKO $P<0.001$ two tailed Mann-Whitney). In the presence of $1.8 \mathrm{mM} \mathrm{Ca}^{2+}$ in the extracellular solution, the peak intracellular $\mathrm{Ca}^{2+}$ transients measured with the low-affinity calcium indicator MagFluo4 were $1.009 \pm 0.18 \quad(n=47)$, $0.67 \pm 0.16(n=49), 0.80 \pm 0.25(n=40)$ and $0.82 \pm 0.25(n=47)$ for WT, DKO, JP45 KO and CASQ1 KO, respectively $\left(\Delta F / F_{\mathrm{o}}\right.$ values are expressed as mean \pm s.d., Fig. 1 top panels). The significant decrease of the peak $\mathrm{Ca}^{2}+$ transient in DKO fibres is not due to a lower membrane density of RyRs (Supplementary Fig. S1). The half-time of the decay of the $\mathrm{Ca}^{2}+$ transients in flexor digitorum brevis (FDB) fibres from DKO mice was significantly slower compared with WT $(3.7 \pm 0.7, n=47$ and $4.8 \pm 1.9 \mathrm{~ms}, n=49$ in WT and DKO fibres, respectively. Analysis of variance (ANOVA) $P$-values $<0.0001$; multicomparison Dunnet's post test WT versus DKO $P<0.01)$.

Enhanced ECCE in FDB fibres from DKO mice. The slower decay of the calcium transients in FBD fibres from $\mathrm{DKO}$ mice is not due to a decrease of calcium uptake in to the SR by the $\mathrm{Ca}^{2+}$ pump because we did not observe a reduction of the SERCA1 and SERCA2 expression in DKO mice (Supplementary Fig. S1). The increase of the half-time of the decay of the calcium transient is rather linked to an influx of extracellular $\mathrm{Ca}^{2+}$, as in the presence of $\mathrm{La}^{3+}$, a non-specific calcium channel blocker ${ }^{10}$, the difference in the half-time for the decay of calcium transient between WT and DKO fibres disappears $(3.1 \pm 0.7$ and $3.3 \pm 1.1 \mathrm{~ms}$ for WT and DKO, respectively). The effect of $\mathrm{La}^{3+}$ was much more evident upon stimulation of FDB fibres with repetitive action potentials. In the presence of $\mathrm{La}^{3+}$, the $\mathrm{Ca}^{2+}$ transient amplitude of tetanic stimulation was highest in WT fibres $(1.31 \pm 0.28 ; n=37)$ compared with that of DKO $\left(0.62 \pm 0.14^{*}\right.$, $n=34), \quad \mathrm{JP} 45$ KO $\left(1.05 \pm 0.30^{\S}, \quad n=26\right)$ and CASQ1 $\left(0.70 \pm 0.15^{\star} n=24\right)\left(\Delta F / F_{\mathrm{o}}\right.$ values are mean \pm s.d., ${ }^{\star} P<0.01$, $\S_{P}<0.05$, (multicomparison Dunnet's ANOVA post test, Fig. 1). In CASQ1 null fibres, the summation of $\mathrm{Ca}^{2+}$ transient peaks was dramatically different compared with WT, JP45 null and DKO fibres. After the few initial peaks, which display an amplitude 50\% lower compared with WT, the fused $\mathrm{Ca}^{2+}$ transients in CASQ1 KO fibres rapidly decayed to basal levels. This event reflects depletion of $\mathrm{Ca}^{2+}$ stores due to the ablation of the $\mathrm{Ca}^{2+}$ storage protein ${ }^{23-25}$. However, at variance with CASQ1 null fibres, the double $\mathrm{KO}$ (DKO) fibres exhibit a sustained $\mathrm{Ca}^{2+}$ transient which persisted for the entire duration of the repetitive stimulation in the presence of calcium in the extracellular solution (Fig. 1 middle panels, arrow $\mathrm{Ca}^{2+}$ ).

Depolarization of DKO fibres causes massive $\mathrm{Ca}^{2}+$ influx. The sustained calcium transients evoked by tetanic stimulation in DKO fibres is caused by massive $\mathrm{Ca}^{2}+$ influx, as in the presence of $100 \mu \mathrm{M} \mathrm{La}^{3+}$ in the external solution (Fig. 1 middle panel, arrow $\left.\mathrm{La}^{3+}\right)$, the $\mathrm{Ca}^{2+}$ transient curve overlapped with that of CASQ1 KO fibres. These data unambiguously demonstrate that ablation of JP45 in a CASQ1 null background unveils a robust $\mathrm{Ca}^{2+}$ influx component coupled to membrane depolarization. 


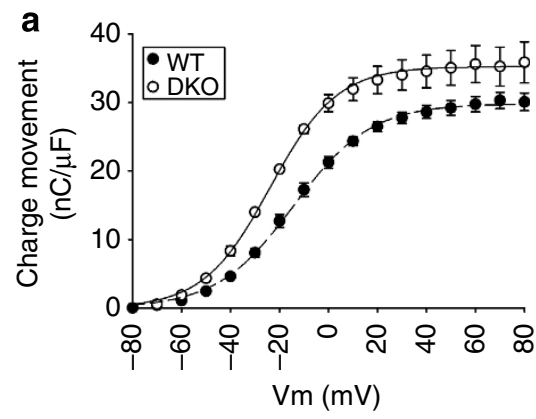

C

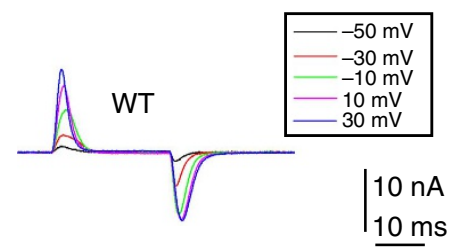

e

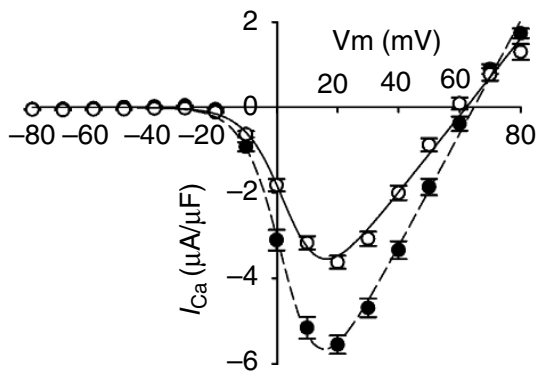

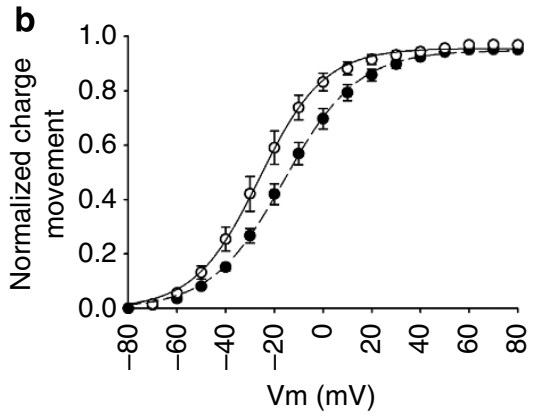

d
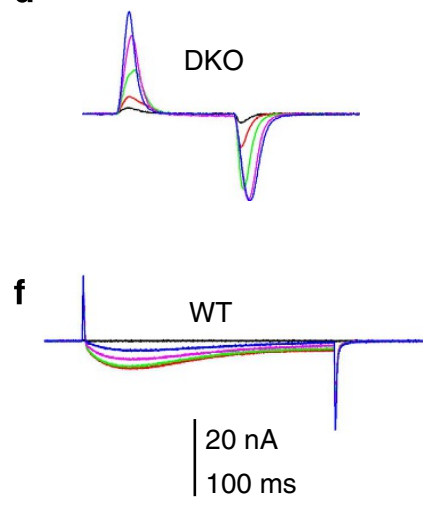

g

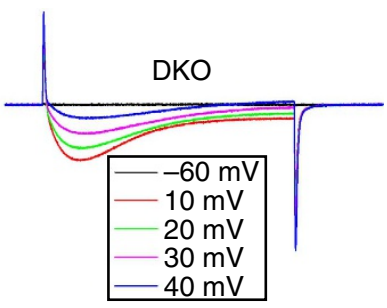

Figure 3 | Voltage dependence of charge movements and $\mathbf{C a}^{2}+$ currents. (a) Charge movement-membrane potential relationship for WT ( $n=13$ ) and DKO $(n=15)$ muscle fibres. Values are mean \pm s.e.m. error bars show s.e.m. (b) Normalized values to maximal charge movement. Values are mean \pm s.e.m. error bars show s.e.m. (c-d) Representative charge movement traces recorded in FDB fibres voltage-clamped in the whole-cell configuration of the patch clamp. Holding potential: $-80 \mathrm{mV}$. Command pulses of $25 \mathrm{~ms}$ duration evoked currents from -80 to $80 \mathrm{mV}$. Selected traces correspond to the steepest part of the curve. Notice the larger amplitude and $10 \mathrm{mV}$ shift of the curve toward more negative potentials in DKO compared with WT mice. (e) Calcium current-membrane voltage relationship. Command pulses of $400 \mathrm{~ms}$ duration evoked currents from -80 to $80 \mathrm{mV}$. Notice the larger current amplitude for DKO $(n=19)$ compared with WT $(n=29)$ mice. Values are mean \pm s.e.m. $(\mathbf{f}-\mathbf{g})$ Representative calcium currents recorded at the indicated membrane voltages. Fitting curves, their respective equations and best fitting parameter values are described in Tables 1 and 2.

This conclusion is also supported by fura-2 manganese quenching experiments performed in FDB fibres (Fig. 1 lower panels). At an excitation wavelength of $360 \mathrm{~nm}$, the $\mathrm{Ca}^{2+}$ independent isosbestic wavelength of fura-2, $\mathrm{Mn}^{2+}$ entry quenches fura-2 fluorescence ${ }^{28}$. We measured the extent of the fluorescence quenching at the end of a 300-ms-long train of pulses at $100 \mathrm{~Hz}$. We found that manganese quenching of fura- 2 fluorescence was $-0.11 \pm 0.039 \quad(n=16), \quad-0.034 \pm 0.021 \quad(n=17), \quad-$ $0.034 \pm 0.011(n=19),-0.027 \pm 0.019(n=35)$ for DKO, WT, JP45 KO and CASQ1 KO fibres, respectively $\left(\Delta F / F_{\mathrm{o}}\right.$ values are mean \pm s.d.). The threefold increase of fura-2 fluorescence quenching by $\mathrm{Mn}^{2+}$ in DKO fibres was abolished by the addition of $50 \mu \mathrm{M}$ nifedipine (Fig. 1 lower panels grey line), a specific inhibitor of $\mathrm{Ca}_{\mathrm{v}} 1.1^{10}$. Skeletal muscle membrane encompasses several molecules that can mediate calcium influx, including the neonatal splice variant $(\Delta 29)$ of $\mathrm{Ca}_{\mathrm{v}} 1.1^{29}$, TRPC3 ${ }^{15}$ and OraI1/Stim 1 ${ }^{14}, \mathrm{Ca}_{\mathrm{v}} 1.2$. We investigated the expression levels of other known calcium influx channels, and we found no changes both in fast and slow DKO fibres (Fig. 2). Altogether, these data support the conclusion that the increase of excitation- coupled $\mathrm{Mn}^{2}+$ entry is mediated by an enhancement of calcium currents through adult form $\mathrm{Ca}_{\mathrm{v}} 1.1^{10}$. The next set of experiments was designed to evaluate the changes in the functional properties of the $\mathrm{Ca}_{\mathrm{v}} 1.1$.

Increase of Cav1.1 channel activity in DKO fibres. The T-tubular system is the membrane compartment richest in $\mathrm{Ca}_{\mathrm{v}} 1.1^{30}$ and high-resolution electron microscopy shows that volume and surface of the T-tubular system in FDB fibres from 1-month-old DKO and WT mice is not different (Supplementary Fig. S2). Thus, the threefold increase of excitation-coupled $\mathrm{Mn}^{2}+$ entry is not fully explained by changes of T-tubular membrane extensions or by a small increase of the $\mathrm{Ca}_{\mathrm{v}} 1.1$ membrane density (Supplementary Fig. S1), but rather could be consistent with a modification of the channel activity of $\mathrm{Ca}_{\mathrm{v}} 1.1$. To examine this possibility, we investigated the capacitive and $\mathrm{Ca}^{2}+$ currents of $\mathrm{Ca}_{\mathrm{v}} 1.1$ in FDB fibres from DKO and WT mice by using the whole-cell configuration of the patch-clamp technique. Intact FDB fibres from DKO mice show $10 \mathrm{mV}$ shift to more negative 
Table 1 | Best-fitting parameters describing the voltagedependence of charge movement.

\begin{tabular}{lccc} 
& $\mathbf{Q m a x}\left(\mathbf{n C} \boldsymbol{\mu} \mathbf{F}^{-\mathbf{1}}\right)$ & $\boldsymbol{V}_{\mathbf{Q} \mathbf{1} / \mathbf{2}}(\mathbf{m V} \mathbf{)}$ & $\boldsymbol{K}$ \\
\hline WT $(n=13)$ & $30 \pm 8$ & $-14 \pm 2.2$ & $16 \pm 1.5$ \\
DKO & $35 \pm 11$ & $-24 \pm 1.7$ & $14 \pm 1.9$ \\
$(n=15)$ & $(P=0.724)$ & $(P=0.001)$ & $(P=0.426)$ \\
\hline
\end{tabular}

Data points were fitted to a Boltzmann equation of the form

Qon $=\mathrm{Qmax} /\left[1+\exp \left(V_{01 / 2}-V_{m}\right) / K\right]$, where $\mathrm{Qmax}$ is the maximum charge, $V m$ is the membrane potential, $V_{1 / 2}$ is the charge movement half-activation potential and $K$ is the steepness of the curve as described in ref. 27. The number of FDB fibres from three to four mice is between parentheses. Results are expressed as the mean \pm s.e.m. Statistical significance was assessed using Student's $t$-test. The $\alpha$-level was set at $P=0.05$.

\begin{tabular}{|c|c|c|c|c|}
\hline & Gmax (nS/nF) & $V_{1 / 2}(\mathrm{mV})$ & $\operatorname{Vr}(\mathrm{mV})$ & $z$ \\
\hline WT $(n=29)$ & $90 \pm 8$ & $4.7 \pm 2.5$ & $62 \pm 3.1$ & $3.9 \pm 0.6$ \\
\hline $\begin{array}{l}\text { DKO } \\
(n=29)\end{array}$ & $\begin{array}{c}132 \pm 12 \\
(P=0.005)\end{array}$ & $\begin{array}{c}3.8 \pm 1.9 \\
(P=0.775)\end{array}$ & $\begin{array}{c}64 \pm 4.4 \\
(P=0.712)\end{array}$ & $\begin{array}{c}4.0 \pm 0.8 \\
(P=0.921)\end{array}$ \\
\hline
\end{tabular}

Data points were fitted to the following equation: ICa $=G \max (V-V m) /\left\{1+\exp \left[z F\left(V_{1 / 2}-V\right) /\right.\right.$ $R T]$, where Gmax is the maximum conductance, $V$ is the membrane potential, $V r$ is the reversal potential, $V_{1 / 2}$ is the half-activation potential, $z$ is the effective valence, $F$ is the Faraday constant, $R$ is the gas constant and $T$ is the absolute temperature $(296 \mathrm{~K})$ as described in ref. 43 . The number of FDB fibres from three to four mice is between parentheses. Results are expressed as the mean \pm s.e.m. Statistical significance was assessed using Student's $t$-test. The $\alpha$-level was set at $P=0.05$

potential of the half maximal gating charge, and small nonsignificant increase $(15 \%)$ in maximal gating charge, compared with control (Fig. 3b and Table 1). The small increase of maximal gating charges do not account for the $\sim 45 \%$ increase of in peak $\mathrm{Ca}^{2+}$ current density, which was found in DKO FDB fibres (Fig. 3e). Half-maximal $\mathrm{Ca}^{2+}$ currents in wild-type (WT) and DKO mice were observed at very similar membrane potentials (Table 2). These results demonstrate that enhanced calcium influx is accounted for an increase of the $\mathrm{Ca}_{\mathrm{v}} 1.1$ channel activity.

Skeletal muscle performance is restored in DKO mice. To investigate physiological relevance of the enhanced $\mathrm{Ca}_{\mathrm{v}} 1.1$ channel activity in DKO mice, we measured in vivo muscle performance by assessing spontaneous motor activity (Fig. 4a). Three weeks of training improved skeletal muscle performance in both WT and KO mice, however, the total running distance in JP45 null and CASQ1 null mice was $\sim 40 \mathrm{~km}$ lower compared with WT and DKO mice $(139.7 \pm 2.90 \mathrm{~km}, 118.1 \pm 2.35 \mathrm{~km}$ versus $175.3 \pm 2.96 \mathrm{~km}, 175.5 \pm 4.23 \mathrm{~km}$, respectively). The enhanced Cav1.1 channel activity restored muscle performance in DKO mice despite a low degree of atrophy of fast fibres (Supplementary Fig. S3), and may be a signature of improved muscle strength ${ }^{31}$ mediated by massive $\mathrm{Ca}^{2+}$ influx via $\mathrm{Ca}_{\mathrm{v}} 1.1^{10}$. To investigate this, we studied the mechanical properties of intact extensor digitorum longus (EDL) (Fig. 4b). EDL from WT and DKO were stimulated with a train of tetani at $0.27 \mathrm{~Hz}$. The onset maximal tetanic force normalized per muscle cross-sectional area of EDL from WT and DKO were not significantly different $(327.86 \pm$ $117.53 \mathrm{mN}$ versus $364.64 \pm 76.22 \mathrm{mN}$, respectively; mean \pm s.d. $n=9$ ), whereas the time course of force development of EDL from DKO was dramatically different compared to those of WT. In DKO mice, the first train of repetitive pulses of $350 \mathrm{~ms}$ duration at $100 \mathrm{~Hz}$ caused an initial increase of isometric force and then rapidly decayed to $\sim 20 \%$ of the onset value at the end of the repetitive pulses stimulation (Fig. $4 \mathrm{~b}$, arrow middle panel 'first'). The reduction of force development during trains of action potentials is most likely indicative of poor calcium buffering capacity of SR caused by the ablation of CASQ1, as a similar inability to sustain muscle contraction has been observed in muscles from CASQ1 KO mice ${ }^{24}$ but not in the EDL muscles from JP45 KO mice ${ }^{27}$, which have a normal CASQ1 expression level. Ablation of JP45 in a CASQ1 KO background has a remarkable effect on the peak tension after repetitive tetanic trains at $0.27 \mathrm{~Hz}$. We observed that in the EDL from the DKO mice the isometric tension developed at the end of the last pulse of the train increased up to $300 \%$ of the initial value while a modest decrease was evident in WT mice (Fig. $4 \mathrm{~b}$ arrow middle panel 'last'; lower panels). On the basis of the data reported in Figs. 1 and 3, we reasoned that the ablation of JP45 in the CASQ1 $\mathrm{KO}$ background supports a strong calcium influx component mediated by $\mathrm{Ca}_{\mathrm{v}} 1.1$ channel activity which leads to (i) accumulation of intracellular calcium and to (ii) the improvement of the peak force development after trains of tetanic stimulation. We tested this possibility by examining the effect of $\mathrm{La}^{3+}$ on the dynamics of force development of EDL from DKO mice during trains of tetani. As expected incubation of EDL with an external solution containing $100 \mu \mathrm{M} \mathrm{La}^{3+}$ blocked calcium influx, and the increase of isometric force at the end of each train of pulses at $100 \mathrm{~Hz}$ in DKO and had no effect on WT muscles (Fig. 4b, lower panels). The effect of $\mathrm{La}^{3+}$ in muscles from DKO mice was reversed by re-exposing EDLs to a bathing solution containing $1.8 \mathrm{mM} \mathrm{CaCl}_{2}$ (Fig. 5).

\section{Discussion}

Here we investigated the role of the JP45/CASQ1 complex on the modulation of $\mathrm{Ca}_{\mathrm{v}} 1.1$ function by analysing the functional properties of skeletal muscle fibres from JP45/CASQ1 DKO mice. Our results show that in DKO mice, calcium transients induced by repetitive action potential are supported by massive calcium influx from the extracellular environment. The massive increase of calcium influx is consistent with an enhancement of the $\mathrm{Ca}_{\mathrm{v}} 1.1$ channel activity because: (1) it is inhibited by nifedipine, a blocker of $\mathrm{Ca}_{\mathrm{v}} 1.1$; (2) it does not correlate with an increase in the expression of other know calcium influx channels such as OraI1, TRPC3 and the neonatal isoform of $\mathrm{Ca}_{\mathrm{v}} 1.1$; (3) is associated with a $45 \%$ increase of the $\mathrm{Ca}_{\mathrm{v}} 1.1$ peak calcium current density in intact single FDB fibres. This massive calcium influx via $\mathrm{Ca}_{\mathrm{v}} 1.1$ restores the development of in vitro muscle force of EDL from DKO mice. The maintenance of muscle force in vitro is paralleled by the recovery of muscle performance of DKO mice in vivo. The characterization of the JP45/CASQ1 DKO animal model supports the conclusion that JP45/CASQ1 complex may be a genetically encoded modulator of the $\mathrm{Ca}_{\mathrm{v}} 1.1$ channel activity.

The $\mathrm{Ca}_{\mathrm{v}} 1.1$ complex has a dual function: it acts as (i) voltage sensor which activates, via a mechanical coupling, the RyR, and as (ii) a slow activating voltage-dependent calcium channel. Calcium influx via $\mathrm{Ca}_{\mathrm{v}} 1.1$ channel activity was considered not important for skeletal muscle EC coupling, as it was shown that skeletal muscles can contract for hours in extracellular medium containing very low (sub $\mathrm{nM}$ ) calcium concentrations ${ }^{11}$. The idea that skeletal muscle EC coupling is independent from the influx of extracellular calcium was confirmed later by pharmacological and genetic manipulation of $\mathrm{Ca}_{\mathrm{v}} 1.1$ function ${ }^{32-35}$. However, in evaluating the functional significance of the $\mathrm{Ca}_{\mathrm{v}} 1.1$ channel activity, one can not dismiss results showing that the influx of extracellular calcium in involved in the development of muscle contraction in amphibian and mammalian muscle fibres ${ }^{36,37}$. This apparent discrepancy might be ascribed to different experimental models and conditions that were used to probe the importance of $\mathrm{Ca}_{\mathrm{v}} 1.1$ channel activity in EC coupling. In this study we exploited the JP45/CASQ1 DKO mouse model to 
a

Spont aneous motor activity of WT

CS-1 KO, JP45KO and JP45/CS-1 DKO mice

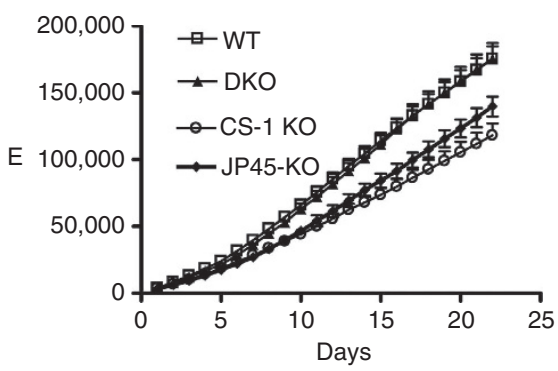

b
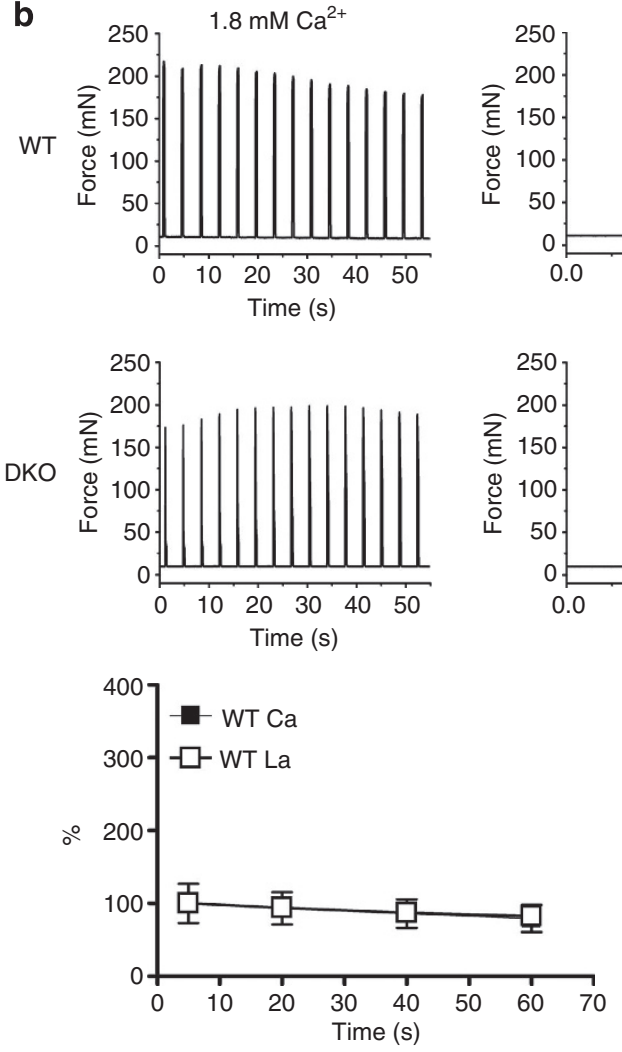
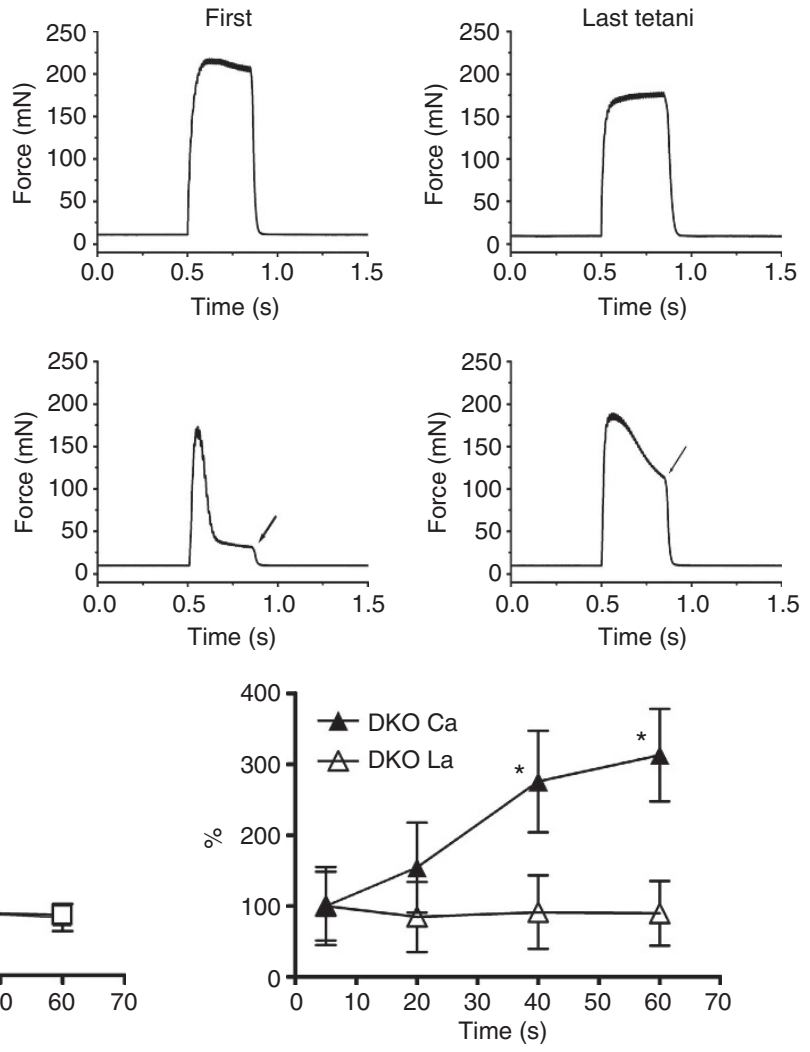

Figure 4 | Skeletal muscle performance of WT and DKO mice. (a) In vivo evaluation of muscle strength. Spontaneous activity in 4-6 week-old WT, DKO, JP45 KO and CASQ1 KO mice individually housed in cages equipped with a running wheel. Data points are expressed as mean \pm s.e.m.; $n=10$ to 13 mice. Overall ANOVA $P$-value $<0.0001$; multicomparison Dunnet's ANOVA post test shows difference: WT versus DKO $P>0.05$; WT versus JP45 KO $P<0.05$; WT versus CASQ1 KO $P<0.01$. (b) Evaluation of tetanic force of intact EDL. Top and middle row of panels: EDLs were triggered by field stimulation in bathing solution containing $1.8 \mathrm{mM} \mathrm{CaCl}_{2}$ with a train of repetitive pulses $(100 \mathrm{~Hz}, 350 \mathrm{~ms}$ duration) at $0.27 \mathrm{~Hz}$ (left panels). Time course of force development of the first and last tetani of the trace displayed in the left panels (middle and right panels). Lower row of panels: after repetitive train stimulation the EDL muscles from control (left panel) and DKO (right panel) mice were incubated for 10 min in a bathing solution containing $100 \mu \mathrm{M} \mathrm{La}{ }^{3+}$ and were then stimulated with repetitive trains of pulses at $0.27 \mathrm{~Hz}$. Data point represents the force developed at the end of $350 \mathrm{~ms}$ duration repetitive pulse stimulation (values are mean \pm s.d. $n=8,{ }^{*} P<0.05$ Mann-Whitney). The increase the force developed at the end of tetanic stimulation in EDL from $\mathrm{KO}$ mice was abolished by $100 \mu \mathrm{M} \mathrm{La}^{3+}$ a blocker of the calcium influx into muscle fibres (compare DKO Ca ${ }^{2+}$ versus $\mathrm{DKO}^{3+}$ ).

investigate to role of $\mathrm{Ca}_{\mathrm{v}} 1.1$ channel activity during EC coupling and its modulation by JP45/CASQ1 complex. Although we are aware that the JP45/CASQ1 KO mouse model may not recapitulate the physiological setting present in mammalian muscle fibres expressing normal levels of both JP45 and CASQ1, our data provide a strong case as to the potential physiological significance of the $\mathrm{Ca}_{\mathrm{v}} 1.1$ channel activity during EC coupling, at least in mutant muscle fibres. The robust calcium influx via $\mathrm{Ca}_{\mathrm{v}} 1.1$ channel activity which was observed during repetitive action potential in JP45/CASQ1 DKO mice results in better contractile function in vitro and, most importantly, in vivo. Such an effect on muscle contractile function could reflect (i) an indirect global adaptive cellular response to the chronic ablation of two important SR proteins, or (ii) result from the lack of specific regulatory mechanism operated by the JP45/CASQ1 complex on the $\mathrm{Ca}_{\mathrm{v}} 1.1$ channel activity. Although we cannot exclude any of the two possibilities, we are confident that our results clearly indicate the physiological importance of the dual activity of $\mathrm{Ca}_{\mathrm{v}} 1.1$ during EC coupling of the DKO muscle fibres. In this mouse model $\mathrm{Ca}_{\mathrm{v}} 1.1$ clearly operates not only as the voltage sensor that activates RyR (Fig. 2), (ii) but also as calcium influx channel which contribute to maintain an adequate level of 

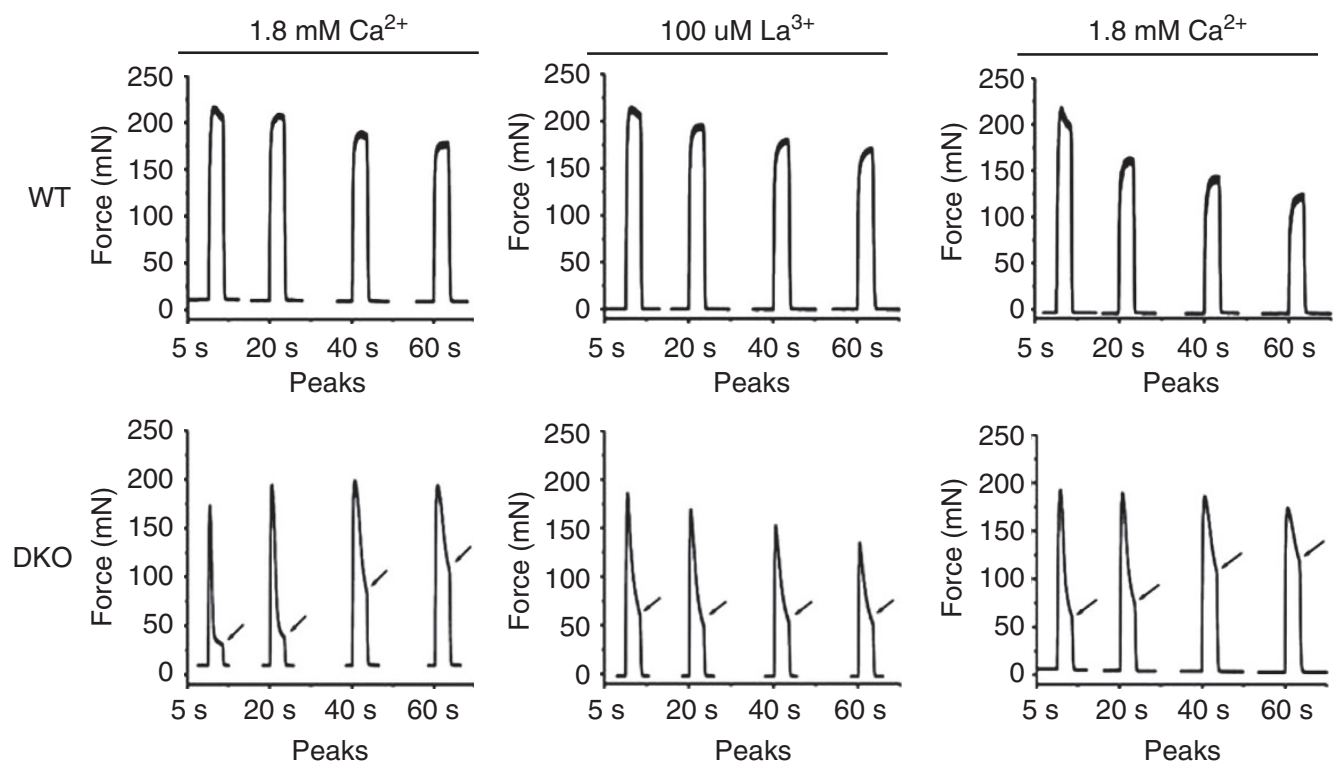

Figure 5 | Tetanic contraction of EDL from WT and JP45/CASQ1 double KO mice. EDL from wild-type and DKO were first incubated in a Tyrode's solution containing $1.8 \mathrm{mM} \mathrm{CaCl}$. Maximal tetanic force was triggered by field stimulation 28 with a train of repetitive pulses (100 Hz of $350 \mathrm{~ms}$ duration) at $0.27 \mathrm{~Hz}$. Tetani at 5, 20,40 and $60 \mathrm{~s}$ are shown. The same stimulation protocols was applied to muscle which were incubated for 10 min in a bathing solution containing $100 \mu \mathrm{M} \mathrm{La3}+$ (traces WT La3 + and DKO La3 +). The increase the force developed at the end of tetanic stimulation in EDL from KO mice was abolished by $100 \mu \mathrm{M} \mathrm{La3}+$ a blocker of the calcium influx into muscle fibres (compare DKO left panel with middle panel). The effect of La3 + was reversed by 10 min long exposure of EDL muscles to a bathing solution containing $\mathrm{Ca} 2+$ (right panels).

releasable SR calcium content during sustained muscle activity evoked by tetanic stimulation (Fig. 3). These data imply that the JP45/CASQ1 complex modulate $\mathrm{Ca}_{\mathrm{v}} 1.1$ channel activity also in normal fibres, in particular, it may operate in those conditions which causes a deficit SR calcium load.

On the basis of these data we propose that JP45/CASQ1 complex is genetically encoded modulator of the $\mathrm{Ca}_{\mathrm{v}} 1.1$. channel activity, and that it constitutes a potential target to devise novel therapeutic strategies against the decline of skeletal muscle strength linked to decreased SR calcium content ${ }^{6,7,12}$.

\section{Methods}

Generation JP45 CASQ1 DKO mice. JP45 KO was obtained as described by Delbono et al..$^{27}$. CASQ1 KO mice were obtained as described by Paolini et al. ${ }^{26}$. DKO mice were generated by crossing to each other established JP45 KO and CASQ1 KO lines backcrossed in C57BL6J (Supplementary Fig. S4).

Morphology. Immunohistochemistry of EDL and Soleus was carried out as described by Delbono et al. ${ }^{38}$. EDL and soleus muscles were embedded in OCT, snap-frozen in isopentane, cryosectioned at the mid-belly region $(10 \mu \mathrm{m})$ and mounted on coverslips for immunostaining. For staining mounted sections were air dried, treated with PBS containing $1 \%$ bovine serum albumin (BSA) and $2 \%$ horse serum for $30 \mathrm{~min}$ and incubated overnight at $4-8^{\circ} \mathrm{C}$ with a PBS solution containing $0.01 \%$ Triton X100, $1 \% \mathrm{BSA}, 2 \%$ horse serum, $0.5 \% \mu \mathrm{g} \mathrm{ml}^{-1}$ anti-mouse slow myosin heavy chain (MAB 1628, Millipore, Billerica, MA), $2 \mu \mathrm{g} \mathrm{ml}^{-1}$ anti rat $\alpha$ laminin (MAB1914, Millipore). Sections were then washed with PBS for $15 \mathrm{~min}$ four times, and incubated at room temperature for $40 \mathrm{~min}$ with a PBS containing Alexa Fluor 488 anti-mouse $\operatorname{IgG~Ab}\left(2 \mu \mathrm{g} \mathrm{ml}^{-1}\right)$ and Cy3 anti rat $\operatorname{IgG~Ab}\left(0.5 \mu \mathrm{g} \mathrm{ml}^{-1}\right)$. After incubating in the secondary Ab, sections were washed with PBS for $15 \mathrm{~min}$ four times, dehydrated with ethanol and mounted using a glycerol medium.

Fluorescence images were imaged using a Leica DM5000B fluorescence microscope and analysed with Analysis software package from Soft Imaging System, Muenster, Germany. Image analysis of muscle sections was performed in four steps: (1) determination of the muscle fibre boundaries, (2) determination of the muscle fibre cross-sectional area, (3) calculation of the per cent of muscle fibres positive for anti MHC I Ab and (4) determination of the per cent of muscle fibres negative for anti MHC I Ab staining. The muscle fibre cross-sectional area was determined using the minimal 'Feret's diameter' (the minimum distance of parallel tangents at opposing borders of the muscle fibre). High-resolution electron microscopy was carried out as described by Paolini et al. ${ }^{26}$ Volume and surface of the transverse tubule (TT) network (see Table in Supplementary. Fig. 4) were determined using the wellestablished stereology point and intersection counting techniques ${ }^{39,40}$ in EM micrographs taken at $\times 14,000$ of magnification. (a) Measurement of relative fibre volume occupied by TT. After covering the images with an orthogonal array of dots at a spacing of $0.20 \mu \mathrm{m}$, the ratio between numbers of dots falling in the TT lumen and the total number of dots covering the whole image represent the relative volume of fibre occupied by the TT. (b) Measurement of TT surface area to volume. The images were covered with two sets of grid lines separated by a distance of $0.24 \mu \mathrm{m}$ and intersecting at right angles. The frequency of intersections between the membrane of interest (TT profiles) and the grid lines was counted. The ratio of TT surface area to volume was obtained from the formula $C / 2 d P$ test, where $C$ is the number of intersections, $d$ is the spacing between the grid lines, and $P$ test is the number of grid intersections in the test area.

Gene expression analysis. Expression of neonatal $\Delta 29$ isoform of $\mathrm{Ca}_{\mathrm{v}} 1.1$ was detected by semiquantitative RT-PCR ${ }^{41}$. Total RNA was extracted from homogenized mouse muscle tissues EDL and SOL, and cultured C2C12 myotubes using TRIzol reagent. Eight hundred nanograms of RNA were first reverse transcribed into CDNA; the Cav1.1 cDNA was amplified by PCR using primers ${ }^{29}$, which span exons 27-34: forward 5'-AGTCGGAGCAGATGAACCAC-3' and reverse $5^{\prime}$-ATGGCCTTGAACTCATCCAG- $3^{\prime}$. The PCR amplification conditions were $95^{\circ} \mathrm{C}$ for $5 \mathrm{~min}$, followed by $37 \mathrm{cycles}$ of $94{ }^{\circ} \mathrm{C}$ for $40 \mathrm{~s}, 51^{\circ} \mathrm{C}$ for $40 \mathrm{~s}$ and $70^{\circ} \mathrm{C}$ for $1 \mathrm{~min}$, followed by a 5 -min extension at $72^{\circ} \mathrm{C}$. The RT-PCR products encoding the adult and neonatal $\left(\mathrm{Ca}_{\mathrm{v}} 1.1 \Delta 29\right)$ isoforms are 790-bp long (upper band) and (lower band) 733 bp long, respectively.

Analysis of total SR and muscle strength assessment. Total SR membranes were prepared ${ }^{22}$ starting from a $20 \%$ skeletal muscle total homogenate; this was sedimented at $3,000_{\text {gmax }}$ for $10 \mathrm{~min}$ and the resulting supernatant was centrifuged at $15,000_{\text {gmax }}$ for $20 \mathrm{~min}$ to remove the myofibrillar protein components. The $15,000_{\text {gmax }}$ supernatant was then centrifuged for $60 \mathrm{~min}$ at $100,000_{\text {gmax }}$ to isolate the total SR (microsomal) pellet. SDS-polyacrylamide electrophoresis and western blot of total SR proteins were carried out as described by Anderson et al. ${ }^{22}$ Blots were probed with a polyclonal primary $\mathrm{Ab}$ followed by peroxidase-conjugated secondary antibodies. The immunopositive bands were visualized by chemiluminescence using the Super Signal West Dura kit from Thermo Scientific. Densitometry of the immunopositive bands was carried out by using BioRad GelDoc 2000. $\left[{ }^{3} \mathrm{H}\right]-\mathrm{PN} 200-110$ and $\left[{ }^{3} \mathrm{H}\right]$-Ryanodine binding was carried out according to Anderson et al. ${ }^{42}$ Briefly, total SR membranes were incubated for $1 \mathrm{~h}$ in the dark in a solution containing $50 \mathrm{mM}$ Tris- $\mathrm{HCl} \mathrm{pH} \mathrm{7.5,10} \mathrm{mM} \mathrm{CaCl}_{2}$ plus protease inhibitor cocktail (ROCHE cat. no. 05892953001), 0.05-5 nM PN200-100 and $(+)-\left[5-m e t h y l-{ }^{3} \mathrm{H}\right]$. The samples were then filtered through Whatman glass microfibre GF/B filters by Millipore manifold filtering apparatus, rinsed three times 


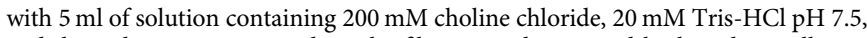
and the radioactivity retained on the filters was determined by liquid scintillation counting. $\left[{ }^{3} \mathrm{H}\right]$-ryanodine binding was carried out by incubating total SR membranes for $12-16 \mathrm{~h}$ at room temperature with $20 \mathrm{mM}$ HEPES $\mathrm{pH} 7.4,1 \mathrm{M}$ $\mathrm{NaCl}, 5 \mathrm{mM}$ AMP, $20 \mu \mathrm{M} \mathrm{CaCl}_{2}, 0.05-10 \mathrm{nM}\left[{ }^{3} \mathrm{H}\right]$-ryanodine and protease inhibitor cocktail (ROCHE cat. no. 05892953001). Membrane bound $\left[{ }^{3} \mathrm{H}\right]-$ ryanodine was determined by scintillation counting as described above. Nonspecific binding was evaluated in the presence of $1 \mu \mathrm{M}$ unlabelled nifedipine and $10 \mu \mathrm{M}$ unlabelled ryanodine, respectively.Curve fitting was performed using Graph Pad Prism 4 software package. Skeletal muscle performance and mechanical properties of EDL were analysed as described by Debono et al. ${ }^{27}$ Briefly, animals were individually housed in cages equipped with a running wheel carrying a magnet. Wheel revolutions were registered by a reed sensor connected to an I-7053D Digital-Input module (Spectra AG, Egg, Switzerland), and the revolution counters were read by a standard laptop computer via an I-7520 RS-485-to-RS232 interface converter (Spectra AG, Egg, Switzerland). Digitized signals were processed by the 'mouse running' software developed at Santhera Pharmaceuticals, Liestal, Switzerland. To test force in vitro, EDL muscles were dissected and mounted into a muscle testing set-up (Heidelberg-Scientific Instruments, Heidelberg, Germany). Muscle force was digitized at $4 \mathrm{kHz}$ using an $\mathrm{AD}$ Instruments converter and stimulated with $15 \mathrm{~V}$ pulses for $0.5 \mathrm{~ms}$. EDL tetanus was recorded in response to $400 \mathrm{~ms}$ pulses at $10-120 \mathrm{~Hz}$. Specific force was normalized to the muscle cross-sectional area $(\mathrm{CSA})=$ wet weight $(\mathrm{mg}) /$ length $(\mathrm{mm}) \times 1.06$ (density $\mathrm{mg} \mathrm{mm}^{-3}$ ).

Cell electrophysiology recordings and optical recording. FDB fibres from WT and DKO mice were enzymatically dissociated, plated and recorded following published procedures ${ }^{43,44}$. The composition of the pipette solution was $(\mathrm{mM}): 140$ Cs-aspartate; $5 \mathrm{Mg}$-aspartate $2,10 \mathrm{Cs}_{2}$ EGTA (ethylene glycol-bis( $\alpha$-aminoethyl ether)- $N, N, N^{\prime} N^{\prime}$-tetraacetic acid), 10 HEPES ( $N$-[2-hydroxyethyl]piperazine- $N^{\prime}$-[2ethanesulfonic acid]), $\mathrm{pH}$ was adjusted to 7.4 with $\mathrm{CsOH}$. The external solution contained (mM): 145 TEA (tetraethylammonium hydroxide)-Cl, $10 \mathrm{CaCl} 2,10$ HEPES and 0.001 tetrodotoxin. Solution $\mathrm{pH}$ was adjusted to 7.4 with TEA.OH. For charge movement recording, calcium current was blocked with the addition of $0.5 \mathrm{Cd}^{2+}$ plus $0.3 \mathrm{La}^{3+}$ to the external solution ${ }^{43}$. Peak $\mathrm{Ca}^{2+}$ currents were normalized to membrane capacitance and expressed as Amperes per Farad, whereas intramembrane charge movements were calculated as the integral of the current in response to depolarizing pulses and expressed per membrane capacitance as Coulombs per Farad. Fura- $2 \mathrm{Mn}^{2+}$ quenching in intact FDB fibres was carried out as previoulsy described ${ }^{19,28}$. Calcium transients were measured by using the low-affinity fuorescent calcium indicator MagFluo $4^{45,46}$. Briefly, changes in the $\left[\mathrm{Ca}^{2+}\right]_{\mathrm{i}}$ induced by supramaximal field stimulation were monitored in FDB fibres loaded with Mag-Fluo-4/AM in Tyrode's buffer. All experiments were carried out at room temperature $\left(20-22^{\circ} \mathrm{C}\right)$ in the presence of $50 \mu \mathrm{M}$ N-benzyl-ptoluenesulfonamide (BTS) (Tocris) to minimize movement artefacts.

Measurements were carried out with a Nikon ECLIPSE TE2000-U inverted fluorescent microscope equipped with a $\times 20$ magnification objective. Fluorescent signals were capture by a photomultiplier connected to a Nikon Photometer P101 amplifier. Calcium transients were analysed by ADinstrument Chart 5 and Origin.6 programs. Changes in fluorescence were calculated as $\Delta F / F=($ Fmax - Frest $) /$ (Frest). Resting calcium was measured with Indol loaded FDB fibres ${ }^{45}$.

Statistical analysis. We used GraphPad Prims 4.0 software package to perform curve fitting and statistical analysis.

\section{References}

1. Rios, E. \& Pizarro, G. Voltage sensor of excitation-contraction coupling in skeletal muscle. Physiol. Rev. 71, 849-908 (1991).

2. Tanabe, T., Beam, K. G., Powell, J. A. \& Numa, S. Restoration of excitationcontraction coupling and slow calcium current in dysgenic muscle by dihydropyridine receptor complementary DNA. Nature 336, 134-139 (1990).

3. Franzini-Armstrong, C. \& Jorgensen, A. O. Structure and development of E-C coupling units in skeletal muscle. Annu. Rev. Physiol. 56, 509-534 (1994).

4. Manini, T. M. \& Clark, B. C. Dynapenia and aging: an update. J. Gerontol. A Biol. Sci. Med. Sci. 67, 28-40 (2012).

5. Dodson, S. et al. Muscle wasting in cancer cachexia: clinical implications, diagnosis, and emerging treatment strategies. Annu. Rev. Med. 62, 265-279 (2011).

6. Kabbara, A. A. \& Allen, D. G. The role of calcium stores in fatigue of isolated single muscle fibres from the cane toad. J. Physiol. 519, 169-176 (1999).

7. Andersson, D. C. et al. Ryanodine receptor oxidation causes intracellular calcium leak and muscle weakness in aging. Cell Metab. 14, 196-207 (2011).

8. Treves, S. et al. Minor sarcoplasmic reticulum membrane components that modulate excitation-contraction coupling in striated muscles. J. Physiol. 587, 3071-3079 (2009).

9. Nakai, J. et al. Enhanced dihydropyridine receptor channel activity in the presence of ryanodine receptor. Nature 380, 72-75 (1996).
10. Bannister, R. A., Pessah, I. N. \& Beam, K. G. The skeletal L-type Ca2 + current is a major contributor to excitation-coupled Ca2 + entry. J. Gen. Physiol. 133, 79-91 (2008).

11. Armstrong, C. M., Bezanilla, F. M. \& Horowicz, P. Twitches in the presence of ethylene glycol bis( -aminoethyl ether)-N,N'-tetracetic acid. Biochim. Biophys. Acta. 267, 605-608 (1972).

12. Pan, Z. et al. Dysfunction of store-operated calcium channel in muscle cells lacking mg29. Nat. Cell Biol. 4, 379-383 (2002).

13. Kurebayashi, N. \& Ogawa, Y. Depletion of $\mathrm{Ca} 2+$ in the sarcoplasmic reticulum stimulates $\mathrm{Ca} 2+$ entry into mouse skeletal muscle fibres. J. Physiol. 533, 185-199 (2001).

14. Yarotskyy, V. \& Dirksen, R. T. Temperature and RyR1 regulate the activation rate of store-operated $\mathrm{Ca}^{2}+$ entry current in myotubes. Biophys. J 103, 202-211 (2012).

15. Launikonis, S. \& Rios, S. Store-operated $\mathrm{Ca} 2+$ entry during intracellular $\mathrm{Ca} 2+$ release in mammalian skeletal muscle. J. Physiol. 583, 81-97 (2007).

16. Allard, B., Couchoux, H., Pouvreau, S. \& Jacquemond, V. Sarcoplasmic reticulum $\mathrm{Ca} 2+$ release and depletion fail to affect sarcolemmal ion channel activity in mouse skeletal muscle. J. Physiol. 575, 69-81 (2006).

17. Rios, E. The cell boundary theorem: a simple law of the control of cytosolic calcium concentration. J. Physiol. Sci. 60, 81-84 (2010).

18. Allen, D. G., Lamb, G. D. \& Westerblad., H. Impaired calcium release during fatigue. J. Appl. Physiol. 104, 296-330 (2008).

19. Cherednichenko, G. et al. Enhanced excitation-coupled calcium entry in myotubes expressing malignant hyperthermia mutation R163C is attenuated by dantrolene. Mol. Pharmacol. 73, 1203-1212 (2008).

20. Zhao, X. et al. Azumolene inhibits a component of store-operated calcium entry coupled to the skeletal muscle ryanodine receptor. J. Biol. Chem. 281, 33477-33486 (2006).

21. Hirata, Y. et al. Uncoupling store-operated $\mathrm{Ca} 2+$ entry and altered $\mathrm{Ca} 2+$ release from sarcoplasmic reticulum through silencing of junctophilin genes. Biophys. J. 90, 4418-4427 (2006).

22. Anderson, A. A. et al. The junctional SR protein JP-45 affects the functional expression of the voltage-dependent Ca2 + channel Cav1.1. J. Cell Sci. 19, 2145-2155 (2006).

23. Canato, M. et al. Massive alterations of sarcoplasmic reticulum free calcium in skeletal muscle fibers lacking calsequestrin revealed by a genetically encoded probe. Proc. Natl Acad. Sci. USA 107, 22326-22331 (2010).

24. Olojo, R. O. et al. Mice null for calsequestrin 1 exhibit deficits in functional performance and sarcoplasmic reticulum calcium handling. PLoS One 6, e27036 (2012).

25. Sztretye, M. et al. Measurement of RyR permeability reveals a role of calsequestrin in termination of $\mathrm{SR} \mathrm{Ca}(2+)$ release in skeletal muscle. J. Gen. Physiol. 138, 231-247 (2011).

26. Paolini, C. et al. Reorganized stores and impaired calcium handling in skeletal muscle of mice lacking calsequestrin-1. J. Physiol. 583, 767-784 (2007).

27. Delbono, O. et al. Loss of skeletal muscle strength by ablation of the sarcoplasmic reticulum protein JP45. Proc. Natl Acad. Sci. USA 104, 20108-20113 (2007).

28. Clementi, E. et al. Receptor-activated Ca2 + influx. Two independently regulated mechanisms of influx stimulation coexist in neurosecretory PC12 cells. J. Biol. Chem. 267, 2164-2172 (1992).

29. Tuluc, P. et al. A Cav1.1 Ca2 + channel splice variant with high conductance and voltage-sensitivity alters EC coupling in developing skeletal muscle. Biophys. J. 96, 35-44 (2009).

30. Fosset, M., Jaimovich, E., Delpont, E. \& Lazdunski, M. $\left[{ }^{3} \mathrm{H}\right]$ nitrendipine receptors in skeletal muscle. J. Biol. Chem. 258, 6086-6092 (1983).

31. Brooks, S. V. \& Faulkner, J. A. Skeletal muscle weakness in old age: underlying mechanisms. Med. Sci. Sports Exerc. 26, 432-439 (1994).

32. Gonzales-Serratos, H., Valle-Aguilera, R., Lathrop, D. A. \& Garcia, M. C. Slow inward calcium currents have no obvious role in muscle excitation-contraction coupling. Nature 298, 292-41982 (1982).

33. Miledi, R., Parker, I. \& Zhu, P. H. Extracellular ions and excitation-contraction coupling in frog twitch muscle fibres. J. Physiol. 351, 687-710 (1984).

34. Melzer, W., Herrmann-Frank, A. \& Lüttgau, H. C. The role of $\mathrm{Ca} 2+$ ions in excitation-contraction coupling of skeletal muscle fibres. Biochim. Biophys. Acta. 1241, 59-116 (1995).

35. Dirksen, R. T. \& Beam, K. G. Role of calcium permeation in dihydropyridine receptor function. Insights into channel gating and excitation-contraction coupling. J. Gen. Physiol. 114, 393-403 (1999).

36. Ildefonse, M., Jacquemond, V., Rougier, O., Renaud, J. F., Fosset, M. \& Lazdunski, M. Excitation contraction coupling in skeletal muscle: evidence for a role of slow $\mathrm{Ca} 2+$ channels using $\mathrm{Ca} 2+$ channel activators and inhibitors in the dihydropyridine series. Biochem. Biophys. Res. Commun. 129, 904-909 (1985).

37. Lamb, G. D. Asymmetric charge movement in contracting muscle fibres in the rabbit. J. Physiol. 376, 63-83 (1986). 
38. Delbono, O. et al. Endogenously determined restriction of food intake overcomes excitation-contraction uncoupling in JP45KO mice with aging. Exp. Gerontol. 47, 304-316 (2012).

39. Loud, A. V., Barany, W. C. \& Pack, B. A. Quantitative Evaluation of Cytoplasmic Structures in Electron Micrographs. Lab. Invest. 14, 996-1008 (1965).

40. Mobley, B. A. \& Eisenberg, B. R. Sizes of components in frog skeletal muscle measured by methods of stereology. J. Gen. Physiol. 66, 31-45 (1975).

41. Vukcevic, M., Spagnoli, G. C., Iezzi, G., Zorzato, F. \& Treves, S. Ryanodine receptor activation by $\mathrm{Ca} v 1.2$ is involved in dendritic cell major histocompatibility complex class II surface expression. J. Biol. Chem. 283, 34913-3422 (2008).

42. Anderson, K., Cohn, A. H. \& Meissner, G. High-affinity $\left[{ }^{3} \mathrm{H}\right] \mathrm{PN} 200-110$ and $\left[{ }^{3} \mathrm{H}\right]$ ryanodine binding to rabbit and frog skeletal muscle. Am. J. Physiol. 266, C462-C466 (1994).

43. Wang, Z. M., Messi, M. L. \& Delbono, O. Patch-clamp recording of charge movement, $\mathrm{Ca} 2+$ current and $\mathrm{Ca} 2+$ transients in adult skeletal muscle fibers. Biophys. J. 77, 2709-2716 (1999).

44. Hernández-Ochoa, E. O. \& Schneider, M. F. Voltage clamp methods for the study of membrane currents and SR $\mathrm{Ca}(2+)$ release in adult skeletal muscle fibres. Prog. Biophys. Mol. Biol. 108, 98-118 (2012).

45. Hollingworth, S., Gee, K. R. \& Baylor, S. M. Low-affinity Ca2 + indicators compared in measurements of skeletal muscle Ca2 + transients. Biophys. J. 97, 1864-1872 (2009).

46. Calderón, J. C., Bolaños, P. \& Caputo, C. Myosin heavy chain isoform composition and $\mathrm{Ca}(2+)$ transients in fibres from enzymatically dissociated murine soleus and extensor digitorum longus muscles. J. Physiol. 588, 267-279 (2010).

47. Tomasi, M. et al. Calsequestrin (CASQ1) rescues function and structure of calcium release units in skeletal muscles of CASQ1-null mice. Am. J. Physiol. Cell Physiol. 302, C575-C586 (2012).

\section{Acknowledgements}

This work was supported by funds from Swiss Muscle foundation, A.F.M., S.N.F and Department of Biomedicine University Hospital Basel. This study was also supported by Research Grant no. GGP08153 from the Italian Telethon ONLUS Foundation to F.P. and grants from the NIH/NIA (AG13934 and AG15820) to O.D.

\section{Author contributions}

B.M. and L.B. developed and monitored mouse colony, collected and analysed calcium measurements data; M.V. collected and analysed expression data; R.L. collected and analysed force measurements data; M.T. and H.T. generated mice model; C.P. and F.P provided CASQ1 KO mice and performed structural analysis; O.D., M.L.M., Z-.M.W., M.M. and G.R. collected and analysed electrophysiological data; S.T. collected and analysed biochemical data; and F.Z. took care of conception and design of the experiments, collection and analysis of biochemical, histochemistry and physiological data, and drafting of the manuscript.

\section{Additional information}

Supplementary Information accompanies this paper at http://www.nature.com/ naturecommunications

Competing financial interests: The authors declare no competing financial interests.

Reprints and permission information is available online at http://npg.nature.com/ reprintsandpermissions/

How to cite this article: Mosca, B. et al. Enhanced dihydropyridine receptor calcium channel activity restores muscle strength in JP45/CASQ1 double knockout mice. Nat. Commun. 4:1541 doi: 10.1038/ncomms2496 (2013). 